\title{
Programa Pró-Equidade de Gênero: uma discussão sobre relações entre homens e mulheres na Caixa Econômica Federal
}

\author{
Elisabeth Lisbôa Pinto \\ Centro Universitário Euro-Americano \\ Suylan Midlej \\ Universidade de Brasilia
}

\begin{abstract}
O objetivo deste artigo é discutir em que medida as ações de implementação do Programa Pró-Equidade de Gênero, desenvolvidas na Caixa Econômica Federal (Caixa) após a concessão do "Selo Pró-Equidade de Gênero", têm melhorado as relações entre homens e mulheres nessa instituição financeira. Foi realizada pesquisa qualitativa, a partir de pesquisa documental e entrevistas individuais semiestruturadas, com cinco entrevistados: quatro gerentes de diferentes agências do banco no Distrito Federal, dois homens e duas mulheres, e a Coordenadora do Programa Pró-Equidade de Gênero na Caixa. Os resultados apontam que ocorreram alguns avanços com a implementação do Programa em relação à normatização de comissão paritária de homens e mulheres nas bancas examinadoras de processos seletivos. No entanto, as mulheres ainda se localizam na base da pirâmide organizacional da Caixa.
\end{abstract}

Palavras-chave: implementação de política pública; gênero; Caixa Econômica Federal.

Programa Pro-Equidad de Género: una discusión sobre las relaciones entre hombres y mujeres en la Caixa Econômica Federal

El objetivo de este artículo es discutir en que medida las acciones de implementación del Programa Pro-Equidad de Género, desarrolladas en la Caixa Econômica Federal (Caixa) después de la concesión del "Sello Pro-Equidad de Género", han mejorado las relaciones entre hombres y mujeres en esta institución financiera. Para tanto, fue realizada investigación cualitativa, a partir de investigación documental y entrevistas individuales semi-estructuradas, con cinco entrevistados: cuatro gerentes de diferentes agencias del banco en el Distrito Federal, dos hombres y dos mujeres, y la Coordinadora del Programa Pro-Equidad de Género en la Caixa. Los resultados apuntan que ocurrieron algunos avances con la implementación del Programa en relación a la normatización de comisión paritaria de hombres y mujeres en las bancas examinadoras de procesos selectivos. Sin embargo, las mujeres aún se localizan en la base de la pirámide organizacional de la Caixa.

Palabras clave: implementación de política pública; género; Caixa Econômica Federal.

Artigo recebido em 16 nov. 2011 e aceito em 20 ago. 2012.

Rev. Adm. Pública - Rio de Janeiro 46(6):1529-50, nov./dez. 2012 
Gender Pro-Equity Program: the discuss about relationships between men and women in the Caixa Econômica Federal

This paper aims to discuss to which extent the actions implemented in the Gender Pro-Equity Program-actions developed in Caixa Econômica Federal (Caixa) after having been granted the Gender Pro-Equity Seal-have improved the relationships amongst men and women in this financial institution. A qualitative research was carried out from documental research and individual, semi-structured interviews with five interviewees: four managers from different Caixa branches in the Federal District, Brazil; two men and two women, and the woman who is Caixa's Pro-Equity Program Coordinator. The results point out that there have been some advances in the implementation of the Program concerning the regulation of the parity commission of men and women in the examining boards of selective processes. However, women are still located in the base of Caixa's organizational pyramid.

Key words: public policy implementation; gender; Caixa Econômica Federal.

\section{Introdução}

Os avanços observados na sociedade em geral no tocante à equidade nas relações de gênero são significativos. No entanto, no campo do trabalho, as desigualdades entre homens e mulheres ainda são evidentes, haja vista os critérios de acesso, remuneração, benefícios e oportunidades de ascensão. Para superar tais desigualdades muito se tem feito, tanto a partir das próprias mulheres, como por meio de políticas públicas governamentais. Resta saber até que ponto essas ações têm conseguido mudar uma situação que se arrasta ao longo de toda a história.

Por parte das mulheres, estas têm procurado reforçar seu nível de escolaridade, inclusive atingindo níveis superiores aos dos homens (Abramo, 2007), seja por iniciativa própria, seja por meio da qualificação oferecida pelas organizações. Contudo, o aumento da escolaridade não tem sido suficiente para eliminar tais desigualdades. Também, muitas têm sido as lutas empreendidas pelos movimentos sociais ligados à temática da igualdade de gênero.

$\mathrm{Na}$ administração pública, a priori, essa desigualdade estaria superada em função da imposição legal a que as organizações estão submetidas. Entretanto, as formas sutis de desigualdade, tacitamente estabelecidas, escapam ao arcabouço legal vigente, sendo possível verificar, por exemplo, que poucas mulheres chegam ao topo da pirâmide hierárquica, exceção feita às profissões de perfil feminino, como é possível se notar nas instituições que prestam serviços sociais, nas escolas etc. (Segnini, 1998).

Ao perceber essa dificuldade, e visando desenvolver políticas públicas de combate à desigualdade nas relações entre homens e mulheres nas organizações públicas, em 2003 o Governo Federal, por meio da Medida Provisória no 103/03, criou a Secretaria Especial de Políticas para as Mulheres (SPM), vinculada à Presidência da República. Tal Secretaria tem como competência formular, coordenar e articular políticas para as mulheres, promover a igualdade de gênero, acompanhar a implementação de legislação de ação afirmativa e definir ações públicas que visem ao cumprimento dos acordos, convenções e planos de ação assinados pelo Brasil. 
Mais precisamente, a SPM formulou o Programa Pró-Equidade de Gênero, instituído pelo Decreto ํㅜㄴ 5.390/2005. É a partir da implementação desse programa governamental que este artigo pretende discutir em que medida essas ações têm melhorado as relações entre homens e mulheres nas organizações financeiras, especialmente na Caixa, após a concessão do "Selo Pró-Equidade de Gênero", distinção outorgada às organizações pela SPM com o intuito de estimular nessas organizações ações em prol da equidade de gênero.

O referencial teórico utilizado para análise da implementação do Programa baseia-se no modelo "policy cycle como aprendizado" (Silva e Melo, 2000) e nas teorias sobre processos de implementação/avaliação. Também são utilizados autores que dialogam nessa direção, como Hill, Rua e outros. Em relação à questão de gênero, são utilizadas as abordagens de Butler, Scott e Segnini.

O artigo está dividido em cinco partes: a primeira é composta por esta introdução; a segunda discute a equidade entre homens e mulheres nas organizações e o conceito de implementação; a terceira apresenta o Programa Pró-equidade de Gênero; a quarta expõe os resultados da pesquisa; e, por fim, as considerações finais.

\section{Metodologia}

Foi realizada pesquisa social, com utilização do método qualitativo devido à natureza dinâmica do campo estudado e das características de fenômeno social (Richardson, 2008), o que se aplica também aos estudos que envolvem gênero, considerado uma categoria de muitas especificidades e de alta complexidade (Butler, 2003). Desse modo, optou-se por realizar pesquisa empírica sobre a implementação do Programa Pró-Equidade de Gênero da SPM, tendo como unidade de análise a Caixa, por esta ter participado das duas edições do Programa e ter recebido o Selo Pró-Equidade de Gênero - atributo concedido à organização que cumpre as exigências estabelecidas no Plano de Ação para implementação do Programa.

A coleta de dados combinou dados secundários da SPM e da Caixa, por meio de pesquisa documental, e dados primários, a partir de cinco entrevistas individuais semiestruturadas na Caixa: dois homens (H3 e H4) e duas mulheres (M1 e M2) na função de gerente geral de quatro diferentes agências; e uma mulher (M5), coordenadora do Programa no âmbito da matriz da Caixa no Distrito Federal. As entrevistas ocorreram entre dezembro de 2009 e fevereiro de 2010. Após sistematização dos dados, foi realizada análise de conteúdo, com base na frequência das respostas e posterior categorização de acordo com as temáticas mais exploradas pelos entrevistados, à luz dos objetivos da pesquisa.

\section{Gênero nas organizações}

As teorias feministas têm como pressuposto comum o reconhecimento da dominação masculina nas construções sociais e o esforço para mudar essa dominação. O ponto central que as 
distingue é o conceito de gênero, cuja divergência encontra-se nos elementos que compõem sua constituição e suas relações (Calás e Smircich, 1996). Essa situação expressa a complexidade de gênero, exigindo que suas discussões não fiquem circunscritas ao debate das construções biológicas e aos conceitos de oposição binária, pois "a complexidade do conceito de gênero exige um conjunto interdisciplinar e pós-disciplinar de discursos, com vistas a resistir à domesticação acadêmica dos estudos sobre gênero ou dos estudos sobre as mulheres, e de radicalizar a noção crítica feminista" (Butler, 2003:12).

Para Butler (2003:8), deve-se levar em conta que as mulheres são reprimidas pelas mesmas estruturas de poder por intermédio das quais se busca a emancipação. Por essa razão, é preciso ter uma visão crítica que resgate a origem de gênero, tendo em vista que o poder parece "operar na própria produção dessa estrutura binária em que se pensa o conceito de gênero", sendo premente realizar uma desconstrução do conceito de gênero.

A desconstrução tira o foco da oposição entre homens e mulheres e da ideia de identidade fixa, superando a discussão de igualdade e de diferenças. Gênero pode ser analisado de três posições: histórica, contextual e relacional (Scott, 1995), abordagem que rompe com a construção de relações hierarquizadas entre universo masculino e especificidades femininas.

Ao considerar a dimensão relacional do gênero, há um reconhecimento de que a distinção entre masculino e feminino só pode ser analisada a partir da relação entre os sexos; a dimensão contextual/situacional aponta que os sexos são construções socioculturais e não biológicas, variando de acordo com a cultura que expressam; já a dimensão histórica destaca que o gênero é resultado de sua contextualização histórico-social compreendendo gênero como construção social remetendo a uma concepção de mulher e homem ligados a raça, religião, classe, cultura e relações de poder político e econômico (Scott, 1995).

A desigualdade de tratamento e de oportunidades que permanece no cotidiano das organizações pode ser percebida inclusive no setor público. Isso ocorre por várias razões, como a dupla jornada de trabalho que caracteriza a divisão de trabalho entre homens e mulheres e entre o público e o privado (Abramo, 2007) e possibilitam compreender a desigualdade porque nela gênero é entendido na divisão de trabalho como classe e ideologia, na relação entre trabalho manual e intelectual (Segnini, 1998), refletindo no acesso, na remuneração, nos benefícios e no processo de ascensão nas atividades.

A segmentação do trabalho no contexto bancário tem na jornada de trabalho um dos aspectos característicos do processo, pois o tempo parcial significa atividades mais simples e repetitivas que se constituem na visão interna como "acomodação", não apresentando perspectiva de ascensão na carreira profissional, lugar geralmente ocupado pelas mulheres. Os trabalhos que apontam para ascensão profissional em níveis mais elevados na hierarquia organizacional, em geral, são atividades de tempo integral. Esse é um modo de marginalizar a mulher por meios sutis de dominação, tendo em vista que, para conseguir realizar o trabalho, privado e público, a tendência é que a mulher opte profissionalmente pelas atividades de tempo parcial (Segnini, 1998). Isso pode refletir o descompasso entre o quantitativo de mulheres nas instituições e o pequeno número das que ascendem a postos mais altos na hierarquia. 


\section{Programa Pró-Equidade de Gênero: uma política afirmativa}

O contexto de desigualdade das relações entre homens e mulheres impulsionou o surgimento do movimento sindical da década de 1990 e o avanço de ações afirmativas quanto à equidade de gênero (Brasil, 2005). Gomes (2001:40) define ações afirmativas como um "conjunto de políticas públicas e privadas de caráter compulsório, facultativo ou voluntário, concebidas com vistas ao combate à discriminação racial, de gênero e de origem nacional". Para o autor, essas ações afirmativas podem ser utilizadas para "corrigir os efeitos da discriminação praticada no passado, tendo por objetivo a concretização do ideal de efetiva igualdade de acesso a bens fundamentais, como a educação e o emprego".

Em 1988, a Constituição Federal consolida várias conquistas que expressam a luta das mulheres, tais como salários iguais para serviços iguais, licença maternidade, licença-paternidade etc. A nova Carta trouxe como um de seus princípios a promoção da igualdade entre homens e mulheres.

Assim, a incorporação da dimensão gênero na agenda governamental foi feita por meio dos movimentos sociais e pela pressão exercida pelos fóruns internacionais. Bandeira (2005:9) afirma ainda que políticas públicas de gênero implicam e envolvem tanto a diferenciação dos processos de socialização entre feminino e masculino como a natureza dos conflitos e das negociações produzidos nas relações interpessoais entre homens e mulheres e internamente entre homens ou entre mulheres. "Também envolvem a dimensão da subjetividade feminina que passa pela construção da condição de sujeito".

Esse contexto de desigualdade de gênero tem levado o Poder Público a formular políticas para tentar sanar esse problema nas organizações, a exemplo da Política Nacional para as Mulheres, aprovada na I Conferência Nacional para as Mulheres, realizada em Brasília, no período de 15 a 17 de julho de 2004, e na II Conferência, que ocorreu nos dias 17 a 20 de agosto de 2007, em Brasília (DF). Essa política tem como princípio a equidade de gênero e "reitera o acesso de todas as pessoas aos direitos universais e a adoção de ações afirmativas voltadas para grupos historicamente discriminados", de acordo com o II Plano Nacional de Política para as Mulheres (SPM, 2008).

O Programa Pró-Equidade de Gênero foi instituído pelo Decreto ㄲo 5.390/2005, cuja formulação e avaliação estão a cargo da Secretaria Especial de Política para as Mulheres (SPM) da Presidência da República. Teve sua primeira edição no biênio 2005-06 e a segunda em 2007-08. A terceira edição ocorreu no biênio 2009-10, tendo sido concluída em 2011, época em que estava sendo realizada a coleta de dados desta pesquisa.

Os objetivos do Programa são conscientizar e sensibilizar dirigentes, empregadores/as e trabalhadores/as para a promoção da igualdade de gênero, estimular práticas de gestão que promovam a igualdade de oportunidades entre homens e mulheres dentro das organizações, e criar a rede Pró-Equidade de Gênero. É dirigido a empresas e instituições de médio e grande porte dos setores público e privado e sua coordenação é feita pela SPM, Ministério do Planejamento, Orçamento e Gestão (MPOG), Ministério Público do Trabalho (MPT), Organização 
Internacional do Trabalho (OIT), Fundo de Desenvolvimento das Nações Unidas para a Mulher (Unifem) e Conselho Nacional dos Direitos da Mulher (CNDM).

A implementação se dá por meio de adesão voluntária, após a organização apresentar diagnóstico básico para construção de Plano de Ação a ser implementado no âmbito interno da organização, que é pactuado entre esta e o comitê do Programa da SPM. A avaliação se constitui com o cumprimento do plano de ação, que ocorre ao final de cada ano a partir da data de assinatura do Termo de Compromisso. Por fim, a entrega do "Selo Pró-Equidade de Gênero", relativo ao período em referência outorgado às organizações que tiverem alcançado as metas acordadas.

O selo é um atributo que distingue a organização comprometida com o combate à discriminação e com a promoção da igualdade entre homens e mulheres, por um período de um ano, podendo participar em diferentes edições, renovando a sua adesão a cada nova etapa, tendo em vista o formato do Programa. A avaliação é realizada pela SPM em parceria com Unifem e OIT.

O Programa Pró-Equidade de Gênero teve sua primeira edição dirigida às organizações públicas; de 16 organizações participantes, 11 receberam o selo. A Caixa recebeu o Selo PróEquidade de Gênero nas duas edições já avaliadas com as ações de aumentar o número de mulheres e de negros em cargos gerenciais e reconhecer as unidades regionais com melhores indicadores de gênero. Na segunda edição, ocorrida no biênio 2007-08, o Programa registrou crescimento de 100\% no número de organizações participantes.

A gestão de pessoas da Caixa é conduzida pela Gerência de Responsabilidade Social Empresarial, área responsável pela gestão das desigualdades de gênero, onde está localizado o Programa Pró-Equidade de Gênero, acompanhado diretamente pela presidência da empresa.

\section{Implementação de políticas públicas}

Ao longo da trajetória das políticas públicas no Brasil, a formulação vem acontecendo quase que exclusivamente a partir do aparelho de Estado. A implementação, por sua vez, se constitui de diferentes modos e com a participação de diversos atores. Aqui não serão levantadas as tensões existentes entre formuladores e implementadores de políticas, mas, como ressalta Hill (2006), essa distinção tem levado a problemas metodológicos e práticos durante a implementação. Além do mais, esse processo pode ser bem confuso quando se consideram as duas abordagens de implementação: "de cima para baixo" (top-down) e "de baixo para cima" (bottom-up). Da mesma forma, a avaliação dessas políticas, a depender do modelo de implementação, passa a ter um uso diferenciado, funcionando na maior parte das vezes como a última etapa do ciclo de uma política pública, que poderá funcionar para aperfeiçoar a política depois de corrigir suas rotas.

Ainda de acordo com Hill, há uma ênfase exagerada sobre a diferença entre formulação e implementação, o que consolida uma visão etapista das políticas públicas. Essa diferenciação 
torna-se mais preocupante diante da abordagem "de cima para baixo", em que a intervenção parte do topo e se centra nos mecanismos de controle sobre os agentes implementadores. Isso porque, dirigindo-se às impressões de Pressman e Wildavsky, o autor corrobora que o sucesso ou o fracasso das políticas depende dos vínculos entre as entidades envolvidas nos processos de implementação e do nível de cooperação entre elas.

O modelo "de baixo para cima" é centrado nas "ações" e se volta para a análise de como ocorre a implementação e não de como essa deveria ser controlada. Trata-se de um modelo considerado mais avançado, porém possui limites uma vez que é centrado nos meios e não nos fins, motivo pelo qual não há como identificar metas explícitas que podem, no entanto, ser de fundamental importância para os resultados.

O enfoque "de baixo para cima" se mostra como alternativa aos estudiosos que entendem que nem toda política precisa ter metas mensuráveis (Gapi-Unicamp, 2002). Nos estudos comparativos, o modelo "de baixo para cima" está relativamente livre de premissas predeterminadas. Dessa forma, a análise concentra-se melhor sobre os níveis em que isso ocorre, já que não se trata de mostrar deficiências de implementação, e sim de recriar as políticas (Hill, 2006). Essa recriação encontra força na discricionariedade dos escalões burocráticos, estruturada de modo a permitir que os atores ajam com autonomia e liberdade para escolher as suas ações, o que amplia os espaços de negociação durante o processo de implementação e possibilita a recriação das ações (Gapi-Unicamp, 2002).

Silva e Melo (2000:3) consideram a implementação de programas governamentais uma espécie de "variável central" na explicação do insucesso das políticas. "Revelou-se, portanto, o 'elo perdido' nas discussões sobre a eficiência e eficácia da ação governamental”. No entanto, os próprios autores acreditam que esse diagnóstico fundamenta-se em uma visão inadequada do processo de formulação e implementação de políticas. Uma visão clássica e canônica, em que a implementação constitui uma das fases do policy cycle. Os autores defendem que as avaliações de política pública, programas e projetos devem privilegiar o processo de implementação, em vez de considerá-lo um "elo perdido".

Rua (1998:252) afirma que a separação entre formulação, implementação e avaliação de políticas públicas é um recurso utilizado mais para fins de análise do que um fato real do processo político. Segundo a autora, implementação se refere às ações necessárias para que uma política funcione efetivamente. "Pode ser compreendida como o conjunto de ações realizadas por grupos ou indivíduos, de natureza pública ou privada, com vistas à obtenção de objetivos estabelecidos antes ou durante a execução das políticas".

A autora identifica dois tipos de implementação: administrada e não administrada. O primeiro caso ocorre quando uma política exige a constituição de uma estrutura organizacional complexa para sua execução, a exemplo das políticas de saúde, educação etc. A implementação não administrada, diferentemente, apenas estabelece regras e condições, ficando aos interessados as iniciativas destinadas à sua realização. O exemplo citado por Rua é o Programa de Qualidade e Produtividade (PBQP), criado em 1990 para apoiar a modernização das empresas brasileiras que recebiam uma certificação após sua implementação. Guardadas 
as devidas proporções, considera-se certa similaridade com o Programa Pró-Equidade de Gênero, que também garante às empresas uma espécie de selo de qualidade.

Segundo Rua (1998:254), "quando se trata da realidade efetiva das coisas, a implementação não se distingue do próprio processo de formulação. E, frequentemente, a implementação acaba sendo algo como 'a formulação em processo"'. Com isso, ela quer dizer que na maioria das vezes as decisões formuladas são de natureza geral, levando à necessidade de muitas outras decisões específicas que ocorrem durante a implementação.

Outro aspecto levantado pela autora se refere às políticas com característica de "programas", cujos objetivos e recursos são definidos claramente. Ela aponta como um dos problemas, quando se trata de políticas com essas características, os conflitos advindos da interação desses programas com outros. Isso porque as novas iniciativas podem afetar atividades em andamento, nem sempre sendo possível compatibilizar os novos programas com os antigos, levando a conflitos. Outras vezes, essas novas ações vêm corroborar as antigas, ou algumas delas. Esse foi o caso, por exemplo, da implementação do Programa Pró-Equidade de Gênero na Caixa, em que entrevistados afirmam que essa organização já possuía uma política de pessoal voltada para a diversidade sexual e o Programa trouxe avanços nessa direção.

Diante da complexidade das políticas públicas, torna-se importante a realização de um acompanhamento durante sua implementação para que seja possível obter uma avaliação mais efetiva. Como recomendam os autores, parece ser fundamental a ênfase em um modelo que quebre a visão linear do ciclo de política pública e aposte em uma visão mais sistêmica: implementação como "formulação em processo" (Rua, 1998) e "policy cycle como aprendizado" (Silva e Melo, 2000).

\section{Um novo modelo de avaliação de política pública}

O "policy cycle como aprendizado" é um modelo alternativo construído baseado no tripé formulação, implementação e avaliação, com destaque para a necessidade de dar atenção à implementação no complexo contexto institucional e organizacional brasileiro (Silva e Melo, 2000), devido a particularidades que permeiam as diferenças funcionais e as questões de coordenação e cooperação dentro da área governamental, pois as organizações são o locus onde ocorrem as decisões, uma vez que nelas é que acontecem as implementações e as avaliações (Hill, 2006).

Neste modelo, a implementação é vista como um processo autônomo onde as decisões orientam a formulação de novas políticas e a avaliação não é apenas uma correção de rota, mas uma etapa de aprendizado. O modelo ressalta o policy cycle como campo estratégico onde há relativa indistinção entre os implementadores e os formuladores e entre stakeholders (grupos envolvidos nas políticas públicas e nelas interessados) e a população-alvo do Programa.

Os autores destacam a importância dos mecanismos de coordenação interinstitucional para a implementação de políticas públicas em ambientes democráticos onde diferentes atores são implementadores. O policy cycle é representado pelas redes complexas de atores que 
sustentam a política e pelos pontos de elevada criticidade no que se refere à coordenação e aos recursos institucionais, diante da diversidade dos atores envolvidos que levam a situações tensas, gerando momentos de crise, cuja superação representa a ocasião de aprendizagem dentro da dinâmica do programa.

Quanto à avaliação de uma política pública, essa pode ser feita de duas maneiras: somativa, utilizada quando são estabelecidas metas para que possam ser verificados os impactos e a efetividade; e formativa, voltada para o apoio e o fortalecimento dos programas (Silva e Costa, 2002). Ou seja, o foco não se direciona para os valores e os objetivos dos tomadores de decisão, mas para um acordo satisfatório entre os interesses envolvidos (Rua, 1998).

As avaliações formativas são voltadas para análise e produção de informação sobre as etapas de implementação. Além disso, geram informações para aqueles diretamente envolvidos com o programa. Nesse caso, há uma aproximação com o modelo policy cycle. As somativas são relacionadas à análise e à produção de informações sobre etapas posteriores. São realizadas quando o programa está sendo implementado há algum tempo ou após a implementação, para verificar a efetividade e fazer o julgamento do valor geral (Cohen e Franco, 2004).

Será possível notar na seção seguinte a aproximação dos modelos de implementação/ avaliação expostos com a realidade da implementação do Programa Pró-Equidade de Gênero na Caixa.

\section{Resultados}

Como dito anteriormente, este trabalho realizou pesquisa de campo na Caixa e entrevistou quatro gerentes de agência e a coordenadora do Programa Pró-Equidade de Gênero da Caixa com o objetivo de compreender em que medida as relações entre homens e mulheres têm melhorado com a implementação do Programa Pró-Equidade de Gênero na Caixa Econômica Federal. Como resultado, serão apresentadas as categorias analisadas a partir das comunicações dos entrevistados, mas também com base na pesquisa documental realizada.

\section{Percepção sobre o Programa Pró-Equidade de Gênero}

Quanto à dimensão de gênero na política de gestão de pessoas, de um modo geral, os gerentes responderam que "gênero" não é algo novo na Caixa, uma vez que faz parte da sua política interna desde a década de 1990. Isso está presente, por exemplo, nos documentos: "o combate ao preconceito e à discriminação tem respaldo no próprio Planejamento Estratégico, que prevê a formulação de políticas promotoras da igualdade de oportunidades — inclusive por meio de ações afirmativas" (Brasil, 2010).

Com base nos depoimentos coletados, observa-se que todos os respondentes conhecem a política de diversidade da Caixa e manifestaram ter familiaridade com o termo gênero, o qual é tratado com certa naturalidade e sem preconceitos aparentes. Os homens, mais do que as mulheres, consideram importante a chegada do Programa: 
A política de pessoal da Caixa é muito boa. Nunca me senti discriminada. Antes era mais difícil, sim, não vou dizer que foi fácil, não. Agora está melhor! (M1)

Isso tá bem dentro do grupo, isso aqui é muito tranquilo e é muito natural. Eu não consigo enxergar, pode até ser falha minha, mas eu não consigo enxergar essa diferenciação [entre os gêneros] porque se a gente quiser todo mundo pode participar. (M2)

Essa questão da equidade de gênero hoje é levada em bastante consideração. Valoriza-se muito esse novo mapa da sociedade. (H3)

A empresa sempre teve esse viés de certa valorização do empregado, mas nos últimos tempos houve um foco maior nisso. Uma valorização maior das pessoas e uma valorização maior desse Programa. (H4)

Foi possível constatar uma diferença entre mulheres e homens também no que diz respeito à presença e disseminação do Programa. Enquanto as primeiras não manifestaram interesse ou conhecimento sobre o conteúdo do Programa, os homens o consideram conhecido entre os empregados.

Eu nunca vi isso como um Programa na Caixa. Talvez até porque a gente nunca teve esse problema, não causou nenhum impacto, nenhuma diferença não foi uma coisa impactante. (M1)

As ações começam lá [tom de distância] na matriz. Quando elas vão chegar aqui, nossa senhora! Já passou por muita coisa. Essa ação foi muito pouco discutida aqui. Pra chegar ao ponto de venda [nas Agências] na ponta falta o povo [empregados] saber mais sobre isso. Então eu acho que falta mesmo dizer mais, falta conversar mais, falta mostrar mais. (M2)

A informação sobre o Programa é bastante disseminada através de e-mails e na comunicação interna. (H3)

Na verdade, houve uma sensibilização por parte da empresa, com todos os funcionários através de e-mails, de revistas etc. (H4)

No entanto, é possível notar que os homens, ao comentarem o Programa, ficam restritos a citar a forma de divulgação sem tecer qualquer comentário sobre o seu conteúdo. As mulheres, por sua vez, disseram de forma clara e direta que o programa não tem a expressão que deveria ter internamente, chegando a tratá-lo com certa banalização. Explicitaram também que apenas alguns sabiam da existência do Programa e que outros, se sabiam de sua divulgação, sequer o mencionaram.

A diferença entre as posições dos/das gerentes respondentes chama a atenção porque não se deu entre os gerentes do Plano Piloto e os das Regiões Administrativas, mas entre os dois gerentes e as duas gerentes. O resultado, assim, foi semelhante ao ocorrido em uma pesquisa exploratória realizada em outra instituição financeira com seis gerentes, em que as respostas de homens e mulheres se assemelhavam não pelo nível da função gerencial, mas pelo gênero (Pinto, 2009).

Foi possível deduzir que os gerentes não expressaram qualquer entusiasmo com o Programa porque, em sua percepção, o que ocorre hoje é a consolidação da política de pessoal 
implantada há algum tempo na empresa, em que a diversidade é tratada com respeito e com olhar de gênero, a exemplo do que afirma H3: "A Caixa tem bastante sensibilidade para praticar há bastante tempo algo que hoje a sociedade está tentando engatinhar e colocar como prática. A Caixa já celebra esse tipo de situação há bastante tempo".

Já para M5, o Programa tem visibilidade e isso pode ser demonstrado de duas formas: valorização do público interno e implantação das comissões Pró-Equidade de Gênero, Igualdade Racial, Pessoas com Deficiências e LGBT.

Há uma valorização do público interno em todas as peças de publicidade na nossa intranet. Se você ler agora o meu protetor de tela, você vai ver empregados da Caixa dando destaque na semana da consciência negra. A implantação das comissões já dá visibilidade de que a política existe. Na região Norte e Nordeste nós tivemos mais dificuldades. Tivemos mais de 23 mil empregados que participaram do processo. Nós temos estados que as integrantes fazem seus debates estaduais, as reuniões trimestrais, discussão nas agências. Nós temos o espaço onde o pessoal produz os seus artigos na intranet em âmbito nacional. Você coloca o empregado como sujeito do processo. (M5)

A entrevistada também deixa claro que, apesar de ainda existirem barreiras em relação às mulheres, o Programa pode ajudar no avanço de melhorias para esse público dentro da Caixa, em especial nas "questões culturais e estruturais, pois são muitos anos; muito tempo de gestão com vícios arraigados" (M5).

$\mathrm{Na}$ verdade, as ferramentas de divulgação estão entre as mais modernas: e-mail, intranet. Contudo, as informações sobre um Programa cuja pretensão é atingir a equidade poderiam ser mais dinâmicas com uma divulgação menos burocrática, por se tratar de tema delicado e culturalmente cristalizado.

\section{O preconceito na ocupação dos cargos de gerência}

Os entrevistados falam também das suas visões sobre a relação de subordinação e os preconceitos ainda existentes na ocupação dos espaços de trabalho pelas mulheres, ressaltando que "a discriminação existe" e que, portanto, são necessários mecanismos de controle que possam mitigar o preconceito e a discriminação. Outro aspecto abordado é a importância de uma constante discussão sobre gênero, de forma que a mulher se sinta forte para romper barreiras solidificadas ao longo dos anos. Para H4, "à medida que o público feminino percebe que algumas barreiras foram rompidas por mulheres, elas passam a acreditar mais também”.

M5 reconhece que, embora o discurso das mulheres seja o de não se sentirem discriminadas, o preconceito existe. Ela cita a existência de uma pesquisa interna ${ }^{1}$ que permite supor a presença desse preconceito.

\footnotetext{
${ }^{1}$ Esta pesquisa é de uso interno da CEF e não foi permitida a sua consulta.
} 
Nós fizemos uma pesquisa interna onde empregados diziam: - Olha, não existe problema, as mulheres não participam dos processos seletivos porque não querem, os processos estão abertos. E as empregadas reconheciam: - Nós não participamos dos processos porque nós temos que cuidar de casa, nós temos que cuidar de filhos, tem a questão da dupla jornada. (M5)

As entrevistadas afirmam que não participam do processo seletivo interno de ascensão porque não querem ou não desejam, mas ao mesmo tempo reconhecem que aquelas que participam ocupam um cargo melhor com muito esforço pessoal:

Na verdade, a gente nunca teve problema na Caixa, eu nunca me senti discriminada. Eu acredito que as pessoas nunca se sentiram discriminadas nem por cor nem sexo. A gente não permite discriminar o outro: se a pessoa é gay ou homossexual, ou se é mulher ou homem. (M1)

Quando a mulher chega em um cargo é porque ela quer realmente sair adiante, ir na frente. É porque ela tem uma vontade muito grande, eu me avalio assim. (M2)

O depoimento de um gerente, por exemplo, sinaliza a necessidade de mecanismos de controle para conter a discriminação de gênero. Outro reconhece que, a partir da discussão interna sobre o assunto, são criadas mais oportunidades para a mulher:

Não tem como você dizer que não tem discriminação. Agora você tem que ter mecanismos de controle. (H3)

A partir do momento que você passa a discutir mais isso, seja na empresa, seja no país, seja no mundo, eu acho que você estimula mais, você promove mais, você cria mais oportunidades para a mulher. (H4)

É possível perceber a desigualdade de gênero em uma agência bancária em função da ocupação dos cargos de gerência. Daí a relevância dos critérios que eles/as utilizam nesses processos. Nesse caso, as mulheres expressam algumas dificuldades para ocupar a função, a exemplo de M1:

Não foi fácil chegar aqui por ser mulher. Eu sempre busquei muito. Eu vejo como um processo natural que alguém tenha discriminação, o problema é dele, não é meu por ser mulher (...). Se tivesse que escolher um homem ou uma mulher, eu escolheria aquela pessoa que eu estivesse precisando, mas se tivesse muito homem, eu escolheria a mulher pra não chocar, dentro da competência dela. Eu levaria em conta [o gênero] sim, hoje eu levaria.

Sobre o processo de preenchimento de vagas para as mulheres exercerem a função de gerente, os respondentes homens acham que é totalmente natural:

Isso na Caixa já é praticado há bastante tempo, uma sequência natural mesmo. A Caixa com bastante sensibilidade já praticava [essa política]. (H3) 
Naturalmente ela [Caixa] trouxe esse viés da participação feminina no corpo gerencial. Isso aconteceu de uma forma natural. Há algum tempo quando você indicasse um gerente ou uma gerente ou uma superintendente, isso de alguma forma chamava atenção: — Ah! é mulher e tal; hoje não. (H4)

Porém, as gerentes, mesmo tendo opiniões semelhantes, acrescentaram em seus depoimentos que as mulheres possuem mais senso de organização e sensibilidade, mas esses atributos não são um diferencial quando do preenchimento da função gerencial.

A constatação do uso da "naturalidade" como forma de não reconhecer a discriminação acaba incorrendo em uma autodiscriminação, que, segundo Yannoulas (2002), retrata uma espécie de vigilância internalizada que assegura o comportamento de acordo com os parâmetros delimitados pela manifestação encoberta ou indireta.

Scott (1995) afirma que no debate econômico os empresários/as empregadores encontraram na teoria das "leis naturais" da oferta e da procura argumentos para fomentar as segregações e discriminações salariais, levando as mulheres a serem dependentes dos homens. Essas atitudes podem explicar a subordinação e rejeição das mulheres que já avançaram nas suas pretensões com as políticas específicas.

Na realidade, esses atributos não são considerados porque as organizações não dispõem de indicadores de gênero que possam orientar as avaliações de pessoas. No entanto, todos/as acham que a competência deva ser o critério para nomeação de qualquer pessoa para a função gerencial, o que exige um bom nível de escolaridade.

Do total de 84 mil funcionários da Caixa, as mulheres correspondem a 46,48\%, e somente 39,75\% ocupam cargos de gestão em relação ao total de gestores (Brasil, 2009). Na perspectiva de superarem barreiras e de estarem cada vez mais aptas aos processos seletivos, elas têm procurado ampliar seus currículos, de modo a consolidar a possibilidade de ascensão na carreira. É importante ressaltar que sua participação em cargos de gestão é crescente no setor formal da economia (Abramo, 2007), sendo a escolaridade uma das condicionantes da participação da mulher no mercado de trabalho (Kon, 2003).

Todos/as os/as entrevistados/as têm nível de pós-graduação, e H3 tem, inclusive, mestrado. Esse alto nível de escolaridade não significa uma situação isolada da Caixa, uma vez que o setor atingiu 66,5\% de bancários com nível superior completo e pós-graduação, bem acima da média nacional, que é de 15,5\% (Febraban, 2008). O nível de escolaridade tão elevado no setor bancário é consequência das relações de trabalho que lhes garantiram a construção de um conjunto de direitos e garantias sociais. A escolaridade provavelmente seja um dos fatores que tem contribuído para o preenchimento de cargos antes restritos ao universo masculino (Segnini, 1998).

As gerentes são conscientes quanto ao fato de as mulheres, além de trabalharem nas organizações, continuarem a ser as responsáveis pela casa e pela família, sem receber o auxílio de seus companheiros; por exemplo:

É muito pesado, muito pesado você trabalhar numa agência. Você pensa nessas metas todas para cumprir. Às vezes a pessoa vem trabalhar e está de cara feia. E eu falo: olha, o cliente não mere- 
ce isso; vá lá embaixo chuta a porta, enche a garrafa de água, passa um batom e vem. Eu acho que isso me faz muito melhor gestora porque eu tenho que lidar em casa com filho que não quer acordar, que não quer ir pra escola, tem que estar sempre negociando; a empregada que não vai e você tem que ajustar sua vida; o marido que está de mau humor; a comida que não está bem. Então se eu dou conta de tudo isso lá, isso me faz muito melhor aqui. (M1)

A mulher diz assim: - Ah! Se eu pegar uma função maior, aí é que não vejo o meu filho. Se eu pegar uma função maior aí é que eu não vou em casa. Eu tenho amigas que falam assim: - Não vou ser Gerente Geral nunca, vai pra reunião todo dia, evento à noite, não tem hora. Tem dias que a coisa é muito pesada. Aí você chega em casa, tem marido, tem filho, tem não sei o quê, é a empregada que faltou. Eu dou conta porque eu tenho apoio em casa. (M2)

A mulher tem seu horário de trabalho, terminou o seu expediente vai buscar filho na escola, vai estudar. Quando você tem a terceira jornada vai cuidar dos filhos, dos familiares e tudo, os homens não. Os homens têm seus joguinhos de futebol nos finais de semana, têm os seus churrasquinhos, têm seu futebol também no meio de semana. Esse relacionamento [com os colegas], essa afinidade, essa proximidade fora do ambiente de trabalho sempre influenciou nos processos seletivos. (M5)

Essa dupla e, muitas vezes, tripla jornadas dificultariam a ascensão profissional da mulher e essa sobrecarga de trabalho muitas vezes as leva a optarem por atividades de carga horária de seis horas (Segnini, 1998).

A responsabilidade com a vida pública e a vida privada faz da mulher, independentemente da classe social, do matiz religioso ou político (Suárez, 1991), uma lutadora incansável. As entrevistas com as gerentes e a coordenadora do Programa deixam claro que não há compartilhamento do trabalho privado com os homens. Percebe-se que esse tipo de comportamento levou a Caixa a incluir em sua agenda a emissão de uma cartilha sobre a divisão e o compartilhamento do trabalho no mundo privado. M5 conclui:

Vamos fazer um relatório sobre a própria vida particular, o que você faz e o que seu marido faz. Quais são as atribuições? Vocês dividem as funções? Por que você tem que ser responsável pelo filho, por que você tem que ser responsável pela casa? Ele ajuda você? Não ajuda? Como você educa seu filho? Seu filho vai jogar futebol e nos seus 16 anos, 18 anos pode sair pra festinha. Tua filha não pode. Então eu realmente discrimino? Não discrimino? Eu sou discriminada? Não sou discriminada? Eu ajudo o processo de discriminação? Então são várias interrogações. E isso é legal, porque o Programa Pró-Equidade de Gênero é pra isso também.

\section{Comissão Pró-Equidade de Gênero}

O Balanço Social da Caixa afirma que a empresa tem como uma de suas decisões "acolher as diferenças, dar oportunidades e valorizar o conhecimento formando não só bons profissionais, mas também cidadãos conscientes da sua missão perante os clientes e a sociedade" (Brasil, 
2004:47). Uma das formas de operacionalização dessas decisões tem sido a estruturação de comissões, como a da Pró-Equidade de Gênero, além das comissões de Igualdade Racial, de Pessoas com Deficiências e de LGBT (Lésbicas, Gays, Bissexuais e Travestis).

Sobre a ação do Programa que propõe o aumento do número de mulheres e de negros em cargos gerenciais, constante dos planos de ação da Caixa para o Programa Pró-Equidade nas edições de 2005-06 e 2007-08, os entrevistados não a comparam propriamente com um sistema de cotas:

Não sou a favor de cotas, nunca fui. A nossa conquista do mundo é um processo natural, independente de cotas ou não. (M1)

Em função do Programa você começa a discutir mais, esse tema começa a estar mais presente, naturalmente você começa a nomear mais. Não que tenha uma cota. (H4)

Para eles, mais importante do que a ação em si, por meio do processo seletivo, é a discussão sobre a equidade de gênero. O debate seria o principal impulsionador das nomeações, que passam a acontecer "naturalmente". Fica nítido, por exemplo, que, para M5, aconteceram avanços com a implementação do Programa Pró-Equidade de Gênero, como a valorização do público interno.

A partir de uma pesquisa interna, M5 coloca que foi formado um grupo de trabalho (GT) que tratava especificamente do processo seletivo interno levando em consideração as mulheres, quando foi alterado o manual normativo RH 040. Nesse normativo ocorreram duas alterações fundamentais: a primeira, nos requerimentos dos processos seletivos em relação ao tempo de substituição das mulheres em função gerencial, porque antes não havia contagem do tempo de trabalho das mulheres como experiência efetiva na função de gestor em caráter de substituição. "Como o período em caráter de substituição não contava como tempo de trabalho na função, ela saía sempre perdendo; hoje o cargo efetivo conta, antes não contava."

A outra alteração foi em relação à última etapa do processo seletivo. "Antes a mesa era composta só de homens, hoje orientamos as Superintendências que a Comissão seja metade homem e metade mulher. Ou seja, uma Comissão Paritária" (M5). A necessidade da Comissão Paritária, segundo a entrevistada, deve-se ao modo de formular a pergunta que, em geral, constrangia as mulheres concorrentes àquela função. "Por exemplo, num processo seletivo, se você perguntar a uma mulher quantos filhos ela tem, essa já é uma forma de discriminação subliminar. Isso não se pergunta para o homem."

Foi efetivado o estabelecimento da inclusão de mulheres nas bancas examinadoras de processos seletivos, equivalentes a $50 \%$ do total de membros, antes constituídas somente por homens. Esta decisão foi tomada pela Caixa após a constatação de forte tendência do discurso masculino nas perguntas feitas nos exames, as quais subliminarmente discriminavam as mulheres, desvirtuando o caráter técnico do processo.

Outra determinação considerada de grande contribuição é a de premiar as direções regionais que valorizem o grupo funcional de mulheres e negros, historicamente colocados à 
margem nos processos seletivos. Segundo dados internos da Caixa, o último resultado registra um aumento de mulheres aprovadas correspondendo a 50,26\% do total (Brasil, 2009).

Mesmo com as opiniões de que a política de gestão de pessoas anterior ao Programa Pró-Equidade de Gênero é suficiente para enfrentar a discriminação em relação às mulheres, deve-se reconhecer que houve mudança interna a partir do Programa, tendo em vista os números crescentes registrados em 2004. O contingente de mulheres em cargos de gestão, que era de 38,80\% (Brasil, 2004), atingiu 39,75\% em 2009 (Brasil, 2009).

Sobre a efetividade do Programa, os entrevistados disseram que a manifestação dos funcionários era mínima e que alguns nem sabiam da existência do Programa. Sobre a reação dos clientes, todos afirmaram que não tinham observado nenhuma manifestação, com exceção de pequenos comentários sobre o fato de haver uma mulher na presidência da empresa. Em contraste com a posição dos gerentes, a coordenadora do Programa reconhece a posição incômoda dos funcionários, manifestada por meio de expressões que revelam o preconceito existente, principalmente por sentirem que os espaços estão ficando mais restritos.

Pode-se verificar que o Programa não atinge os funcionários e funcionárias de forma direta, principalmente porque muitas nem o conhecem. Diante disso, surge a seguinte indagação: como as mulheres poderão transpor as barreiras que existem para a ascensão profissional se a empresa possui um Programa relacionado à equidade e elas nem o conhecem? Isso corrobora as críticas feitas sobre a divulgação do programa, considerada por muitos como ineficaz. Assim, supõe-se que as mulheres localizadas na base da pirâmide organizacional continuam tendo dificuldades para se livrar dos preconceitos semelhantes àqueles existentes antes do Programa.

Por fim, foram coletadas manifestações espontâneas com as considerações gerais dos entrevistados sobre o Programa. Primeiro, foi possível observar a manifestação sobre a regularidade do viés de gênero na política de gestão de pessoas anterior ao Programa Pró-Equidade de Gênero; em seguida, o reconhecimento da atual direção da empresa na conquista e avanços, em especial a normatização da contagem de tempo das mulheres nas substituições de funções e o reconhecimento com pontuação das superintendências que ampliam a quantidade de mulheres e negros em cargo comissionado.

Outro aspecto levantado durante a pesquisa de campo foi sobre a linguagem no feminino e no masculino. Os respondentes sugeriram romper, pelo menos na Caixa, com a concretude da generalização de um discurso que insiste em utilizar sempre palavras masculinas para designar cargos ocupados pelas mulheres. Palavras no feminino são utilizadas a cada momento em que houve a possibilidade de empregá-las, como "presidenta", "superintendenta", "gerenta". Esse comportamento chama atenção porque, de um modo geral, a linguagem masculina predomina como uma manifestação daquilo que é dominante. Na Caixa, o uso de palavras masculinas no feminino mostra, muito provavelmente, a concepção de gênero na política de pessoal, porque como afirma Bandeira (2005:8):

Através da linguagem, a exclusão da mulher é mais visível. O uso do universal masculino como referência genérica acaba associando tudo o que aconteceu e acontece com os seres humanos, 
como sendo realizações masculinas exclusivas (...). A disseminação de uma linguagem masculina exclusiva é naturalizada e incorporada também nas estruturas socioinstitucionais e jurídicas. Tais situações de poder, em relação ao referente masculino, se fazem presentes no planejamento das políticas e das ações públicas, pois, as políticas, programas e ações, mesmo de um governo que se comprometeu com a redução das desigualdades de gênero e com uma abertura às demandas do movimento de mulheres, permanecem endereçados ao homem.

Essa linguagem mostra de alguma forma o rompimento de barreiras construídas socialmente que têm sustentado a desigualdade de gênero. Contudo, observa-se que as pessoas se expressam desse modo com muita convicção, como que para afirmar a necessidade da equidade de gênero.

A concepção de gênero na política de gestão de pessoas da Caixa mostrou-se como um processo que ao longo dos anos vem sendo concebido pelos funcionários que tratam as diversidades de modo natural. Convém, então, reconhecer os avanços conquistados com o Programa. No entanto, de acordo com os princípios de igualdade descritos por Bobbio (1996, apud Cappellin, 2004), a igualdade de oportunidades em uma sociedade competitiva pressupõe a preocupação em disponibilizar a todos o acesso a distintos recursos, e igualdade de fato é a ênfase nos modos por meio dos quais as pessoas entram e permanecem com esses bens. As entrevistadas tinham em torno de sete anos nos cargos.

\section{Implementação do Programa}

O sistema de adesão voluntária do Programa Pró-Equidade de Gênero da SPM e o fato de ele ser constituído de um plano de ação elaborado e implementado pela própria organização rompe com a visão tradicional do ciclo da política pública, que é de ser implementada por um conjunto de leis e normas elaboradas pelos policy makers, na tentativa de reduzir sua complexidade e as tornar mais simples. Nesse caso, pode-se inferir que a implementação do Programa na Caixa, apesar de seus agentes não terem participado do processo decisório no primeiro momento, se deu no modelo "de baixo para cima", contando com a participação da organização na elaboração do plano de ação e de sua própria execução, prerrogativa para formalizar a adesão ao Programa, inclusive, para recebimento do selo Pró-Equidade de Gênero. Ou seja, sua própria concepção previa a participação dos implementadores em seu plano de ação, o que corrobora a visão mais sistêmica da implementação como "formulação em processo", defendida por Rua (1998) e reiterada por Silva e Melo (2000), com o "policy cycle como aprendizado".

O resultado da pesquisa mostra também que o Programa Pró-Equidade de Gênero encaixa-se no tipo de avaliação formativa, aquela que não tem metas mensuráveis, mas ações claras que vão sendo ajustadas durante o processo de implementação. Sua perspectiva não é a de alcançar um resultado quantitativo, mas de interceder na cultura da empresa buscando desenvolver a igualdade de tratamento e de oportunidades de homens e mulheres no trabalho organizacional. 
Como os objetivos do Programa são conscientizar e sensibilizar dirigentes, empregadores/as e trabalhadores/as para a promoção da igualdade de gênero e estimular práticas de gestão que promovam a igualdade de oportunidades entre homens e mulheres dentro das organizações, foi possível perceber seu cumprimento, mesmo que esteja presente no discurso dos entrevistados, sobretudo as mulheres gerentes, que a implementação do Programa é deficitária no tocante à sua divulgação e debate. Esse seria um ponto fraco apontado e outro aspecto da análise.

A implementação do Programa, nesse sentido, se deu em dois aspectos: um positivo, do ponto de vista metodológico, uma vez que o modelo de implementação foi "de baixo pra cima", em que houve a chance de o corpo de funcionários participar do seu plano de ação; e outro negativo, que foi o tímido debate ocorrido entre os funcionários de forma geral, ficando restrito às comissões. Pode-se depreender daí que em relação à implementação dentro da própria Caixa foi utilizado o modelo "de cima pra baixo", o que deixou a desejar, segundo os entrevistados gerentes. Essa visão é rebatida pela coordenadora entrevistada, que considera ter havido debate, conforme foi possível perceber em seus depoimentos, quando, por exemplo, ela cita que "mais de 23 mil empregados participaram do processo" e que houve realização de "debates estaduais e reuniões trimestrais" para discussão da implementação. Outro fator de relevância para a entrevistada foi a formação das comissões, porque só pelo fato de existirem já dariam visibilidade ao Programa.

\section{Considerações finais}

Diante dos resultados desta pesquisa, percebe-se que a Caixa sai à frente de outras instituições financeiras quando avança na implementação de um programa governamental que visa relações mais igualitárias de gênero. Com relação à sua aplicabilidade, o Programa Pró-Equidade de Gênero na Caixa atinge seus objetivos em duas dimensões: criação de normas que geram novas oportunidades para as mulheres; e construção de um Plano de Ação a partir dos empregados da organização implementadora.

No que se refere à normatização criada com a implementação do Programa, uma medida que ajuda a combater a discriminação das mulheres na Caixa é a formação de comissões paritárias de homens e mulheres nas bancas examinadoras de processos seletivos para avaliar a concorrência em função gerencial e a contagem do tempo de trabalho das mulheres com experiência efetiva na função de gestora em caráter de substituição. Com isso, o Programa parece agregar a dimensão da equidade, sobretudo no que se refere à ocupação dos cargos de gerência. O que mudou na prática foram os critérios para ocupação dos cargos de gerência garantidos por meio do manual normativo RH 040 e as comissões do processo seletivo, antes constituídas somente por homens, que passaram a ser paritárias. Isso a partir de uma medida anterior, que foi a implantação da Comissão Pró-Equidade de Gênero.

Quanto à implementação do Plano de Ação do Programa, as ações que constituem o Plano da Caixa não foram submetidas a condições preestabelecidas, ficando a decisão a cargo 
da empresa, onde a formulação e a implementação se aproximam dentro de uma visão mais sistêmica de implementação como "formulação em processo" e "policy cycle como aprendizado", conforme abordado na revisão teórica deste artigo. Esse é um ganho em termos de democratização do processo de implementação de um programa governamental na perspectiva macro. No entanto, pelo fato de serem criadas comissões para tal implementação, o que limita a participação de muitos empregados no processo, houve críticas em relação à pouca divulgação do Programa dentro da Caixa, o que, de acordo com os depoimentos, o torna desconhecido pela maioria.

Ao mesmo tempo que os entrevistados afirmam que o Programa ainda não é conhecido, concordam que a Caixa tem uma política de diversidade em que o viés de gênero já era contemplado, e, por isso, "não há preconceito com as mulheres". Contudo, é preciso relativizar essa "naturalidade", não só em função do discurso, muitas vezes, contraditório, mas no tocante ao que seria o impacto real dessa suposta falta de preconceito: a equidade salarial e de representação de poder das mulheres no ambiente interno. Como foram mostrados, os números ainda deixam a desejar. Somente 39,75\% das mulheres da Caixa ocupam cargos de gestão, o que posiciona as mulheres na base da pirâmide organizacional.

Para que ocorram mudanças concretas em torno da questão de gênero, seriam necessárias mais ações afirmativas, uma vez que os avanços de modo geral são consequências de processo de longo prazo. Mesmo a Caixa estando há pelo menos 20 anos implementando políticas que contemplem a diversidade e participando das três edições do Programa Pró-Equidade de Gênero, no último relatório anual da empresa, o percentual de mulheres em função gerencial baixou para $39,16 \%$.

No geral, percebe-se que a questão da cultura organizacional é mais profunda e não seria a norma simplesmente a solução para a quebra do preconceito e para a equidade de gênero. Na verdade, a cultura organizacional reflete o preconceito existente na sociedade brasileira e as políticas públicas podem ser o primeiro passo para essa mudança. Parece que o Programa conseguiu iniciar esse processo ampliando as discussões internas. Nesse caso, todos os entrevistados foram unânimes em dizer que o debate sobre as questões de discriminação contra a mulher é a saída.

Talvez a implementação do Programa ainda não tenha arregimentado o debate como deveria. Talvez ainda se precise mudar a metodologia da formação de comissões por serem numericamente limitantes. Ocorre que é perceptível que se trata de uma questão complexa e que extrapola a organização estudada, sendo um problema profundo das sociedades em geral, sobretudo a brasileira.

Os resultados encontrados a partir da percepção dos entrevistados sugerem o desdobramento desta investigação, tornando-se fundamental uma segunda etapa da pesquisa de modo que seja possível ampliar a população entrevistada, incluindo outras agências, a fim de perceber se na visão de maior público interno as ações de implementação do Programa estão mudando realmente as relações entre homens e mulheres na Caixa. 


\section{Referências}

ABRAMO, Laís. Inserção das mulheres no mercado de trabalho na América Latina: uma força de trabalho secundária? In: HIRATA, H.; SEGNINI, L. (Org.) Organização, trabalho e gênero. São Paulo: Senac, 2007. p. 22-41.

BANDEIRA, Lourdes. A contribuição da crítica feminista à ciência. Estudos Feministas, Florianópolis, v. 16, n. 1, p. 207-230, jan./abr. 2008.

BANDEIRA, Lourdes. Avançar na transversalidade da perspectiva de gênero nas políticas públicas. Brasília: Cepal; SPM, jan. 2005.

BOBBIO, Norberto. Igualdade e liberdade. Rio de Janeiro: Ediouro, 1996.

BRASIL. Caixa Econômica Federal, Balanço Social - 2004. Disponível em: <ww12.caixa.gov. br/portal/public/acaixa/home/informacoes_financeiras/balancos_demonstrativos/rel_sust_balanco_social>. Acesso em: 8 mar. 2009.

BRASIL. Caixa Econômica Federal. Programa Pró-Equidade de Gênero: plano de ação. 2005.

BRASIL. Caixa Econômica Federal. Programa Pró-Equidade de Gênero: plano de ação. 2007.

BRASIL. Caixa Econômica Federal. Relatório de sustentabilidade - 2009. Disponível em: <ww12. caixa.gov.br/portal/public/acaixa/home/informacoes_financeiras/balancos_demonstrativos/rel_ sust_balanco_social>. Acesso em: 10 abr. 2010.

BRASIL. Caixa Econômica Federal. Relatório de Sustentabilidade - 2010. Disponível em: <ww12. caixa.gov.br/portal/public/acaixa/home/informacoes_financeiras/balancos_demonstrativos/rel_ sust_balanco_social > Acesso em: 20 jun. 2012.

BRASIL. Dieese. Tabela da população economicamente ativa. 2007. Tabela condensada a partir da coleta e análise de dados. Brasil: IBGE, 2005.

BRASIL. Presidência da República. Secretaria Especial de Políticas para as Mulheres. Programa Pró-Equidade de Gênero 2005-2006. 1. ed. Brasília, 2004.

BRASIL. Presidência da República. Secretaria Especial de Políticas para as Mulheres. Programa Pró-Equidade de Gênero 2007-2008. 2. ed. Brasília, 2006.

BRASIL. Presidência da República. Secretaria Especial de Políticas para as Mulheres. Programa Pró-Equidade de Gênero 2009-2010. 3. ed. Brasília, 2008.

BUTLER, Judith. Problemas de gênero: feminismo e subversão da identidade. São Paulo: Civilização Brasileira, 2003.

CALÁS, Marta B.; SMIRCICH, Linda. From "the woman's" point of view: feminist approaches to organizations studies. In: CLEGG, Stewartt R.; HARDY, Cyntia; NORD, Walter (Ed.). Handbook of Organization Studies. London: Sage, 1996. p. 218-257. 
CAPPELLIN, Paolla. A igualdade das oportunidades nas relações de trabalho: a ética de reparação antecede o dever de responsabilidade. In: COSTA, Ana A. et al. (Org.). Reconfiguração das relações de gênero no trabalho. São Paulo: CUT Brasil, 2004. p. 81-118.

COHEN, Ernesto; FRANCO, Rolando. Avaliação de Projetos Sociais. Petrópolis: Vozes, 2004.

FEBRABAN. Relatório Social 2007. 2008. Disponível em: <www.febraban.org.br/Febraban.asp?id_ pagina $=90 \&$ id_texto=0\&palavra=Relatório\%20social $>$. Acesso em: 24 maio 2009.

GAPI-UNICAMP. Metodologia de análise de política pública. Campinas, 2002.

GOMES, Joaquim B. Ação afirmativa e princípio constitucional da igualdade: o direito como instrumento de transformação social. Rio de Janeiro: Renovar, 2001.

HILL, Michael. Implementação: uma visão geral. In: SARAVIA, Enrique; FERRAREZI, Elisabete. (Org.). Políticas públicas. Coletânea. Brasília: Enap, 2006, v. 2, p. 59-110.

KON, Anita. Divisão do trabalho no Brasil: a questão do gênero. Texto para Discussão n. 5/2003. São Paulo: Pepgep/PUCSP, 2003.

PINTO, Elisabeth L.; ANDRADE JR., Hermes; LUZ, Rodolfo P. Pró-Equidade de Gênero: incorporando políticas de ação afirmativa no mundo do trabalho. Revista do Serviço Público, v. 60, n. 4, p. 401-413, out./dez. 2009.

PRESSMAN, Jeffrey; WILDAVSKY, Aaron. Implementation. Berkley: University of California Press, 1984.

RICHARDSON, Roberto. Pesquisa social: métodos e técnicas. 3. ed. São Paulo: Atlas, 2008.

RUA, Maria das Graças. Análise de políticas públicas: conceitos básicos. In: RUA, Maria das Graças (Org.). O estudo da política. Brasília: Paralelo 15, 1998. p. 231-260.

SCOTT, Joan. Gênero: uma categoria útil de análise histórica. Tradução de Guacira Lopes Louro. Educação e Realidade. Porto Alegre, v. 20, n. 2, p. 9-255. jul./dez. 1995.

SEGNINI, Liliana. Relações de gênero no trabalho bancário informatizado. Cadernos Pagu, Campinas, v. 10, p. 147-168, 1998.

SILVA, Pedro L.; COSTA, Nilson R. A avaliação de programas públicos: reflexões sobre a experiência brasileira. Relatório Técnico. Cooperação Técnica BID-Ipea. Brasília: Ipea, 2002.

SILVA, Pedro L.; MELO, Marcus A. O processo de implementação de políticas públicas no Brasil: características e determinantes da avaliação de programas e projetos. Campinas: Nepp/Unicamp, 2000.

SUÁREZ, Mireya. Desconstrução das categorias: "mulher" e "negro". Grupo de Trabalho Temas e Problemas da População Negra no Brasil. In: ENCONTRO ANUAL DA ANPOCS, XV, Caxambu, 1991. Mimeografado.

TREVISAN, Andrei P.; VAN BELLEN, Hans M. Avaliação de políticas públicas: uma revisão teórica de um campo em construção. Revista de Administração Pública, Rio de Janeiro, v. 42, n. 3, p. 529550, maio/jun. 2008. 
YANNOULAS, Silvia C. Dossiê: políticas públicas e relações de gênero no mercado de trabalho. Brasília: CFEMEA; FIG/Cida, 2002.

Elisabeth Lisbôa Pinto é mestra em administração pelo Centro Universitário Euro-Americano.

Suylan Midlej é doutora em sociologia e professora adjunta do Departamento de Administração, do Curso Gestão de Políticas Públicas e do Mestrado Profissional em Administração (MPA/PPGA) da Universidade de Brasília (UnB). E-mail: suylan@unb.br. 